\title{
High Performance Temperature Insensitive Current Mode Rectifier without Diode
}

\author{
Vijay Kumar Anand ${ }^{1}$, Vidya Sagar ${ }^{1}$, Amar Nath Gupta $^{1}$ \\ ${ }^{1}$ (Dept. of ECE, NIT Patna, India)
}

\begin{abstract}
A new current mode precision rectifier is presented. This circuit provides precision rectification for wide range of input signal with low temperature sensitivity. It can work as full wave rectifier as well as half wave rectifier with controllability on action. It can amplify rectified current signal by a bias voltage. Direction of the output current signal can also be controlled by changing the polarity of the bias voltage. It can operate up to tens of Giga Hertz. The rectifier circuit with above features does not use any diode but only two CMOS CCCDTA. Power consumption of the circuit is $601.05 \mu \mathrm{W}$. The performance of the circuit is verified by PSPICE simulations
\end{abstract}

Keywords - CCCDTA, CMOS, current mode circuit, full wave rectifier, half wave rectifier, and PSPICE.

\section{INTRODUCTION}

Precision rectifier is an important building block used in signal processing, instrumentation and conditioning of low level signals. Conventionally, a voltage mode precision rectifier uses diode and op amp [1]. In voltage mode rectifier circuit having diode and op amp, the main problem is that during the conduction and non-conduction transition of the diode, the op amp has to be recovered with a finite low signal $\mathrm{dV} / \mathrm{dt}$ that results in the significant distortion at the time of the zero crossing of input signal. This problem can not be solved by op amp having high slew rate due to low-signal transition problem. If we propose a circuit without diode then this will solve the above said problem.

The circuit using current mode techniques has proved its advantage in many applications, like linear circuits such as active filters and non-linear circuits also such as relaxation oscillators, triggers, and precision rectifiers [2-6]. The main advantages of the current- mode circuits are wide dynamic range of frequency, good linearity over the full operational range, low temperature sensitivity, and low power supply voltages requirement etc. In battery-powered portable equipment there is a need of low-voltage operating circuit. Current-mode techniques suit for this purpose more than the voltage-mode circuits.

Current mode rectifiers are used in peak signal detector, signal polarity detector, AC to DC converter, automatic gain controls system and amplitude demodulation circuit.

Many current mode rectifiers have been reported in the papers [7-24]. Reported rectifiers usually employ two current-mode active elements, two or four diodes, and additional sub circuits. The well-known principle of precise current-conveyor rectification, first reported in [7, 8], uses two CCII+ with four diodes. Modified CCII (DXCCll) were also employed with two diodes in [9]. To eliminate the delay introduced by diodes during switching between ON and OFF states, several types of auxiliary biasing or bias cancellation circuits have been proposed [10-12], that make the concept of circuit more complicated. Another approach of rectification is described in [13], utilizing one CDTA element and four diodes.

Current-mode rectifiers are being modified continuously to use different current mode active blocks like current conveyor [14], current feedback operational amplifier [15] and CDTA etc. We have investigated that the previous papers have proposed the current-mode precision rectifiers [16-18]. But, the magnitude of output signal of those proposed circuits can not be adjusted properly. Additionally, they require a suitable amplifier to achieve required level of output signal. And in case of the requirement of opposite polarity of output signal the circuit design must be changed or may add a current inverter. This reconstruction makes the circuit more complicated. In some circuits, rectifiers use a number of active and passive elements that not suits for realization of circuit into an integrated circuit [19]. In many papers, operations of the rectifier circuits are not independent of temperature.

The aim of this paper is to present a precision current mode rectifier whose output current's magnitude and polarity is electronically controllable. It is done by changing the magnitude and polarity of bias voltage without any addition of more circuits or any change in the circuit design. The circuit design consists of only two CCCDTA. PSPICE simulation results are also shown. They confirm that the proposed circuit provides a wide range of frequency operation with very low temperature sensitivity, controllability of the magnitude of output current and polarity by an input bias voltage. It can also perform well over wide range of input current magnitude. It can be applied in an automatic control by a microprocessor.

The paper is organized as follows: description of the CCCDTA is given in Section II. In section 
III we discuss the proposed circuit of rectifier. Section IV presents simulation results and conclusion is given in section V.

\section{CCCDTA DESCRIPTION}

Current controlled Current differencing transconductance amplifier (CCCDTA) with its schematic symbol is shown in Fig. 1. It is an active circuit element. It has two input terminals $\mathrm{P}$ and $\mathrm{N}$ and two output terminals $\mathrm{Z}$ and $\mathrm{X}$. $\mathrm{I}_{\mathrm{b}}$ and $\mathrm{V}_{\mathrm{ss}}$ are biasing terminal for bias and control on action respectively. Equivalent circuit symbol of CCCDTA is shown in Fig. 2.

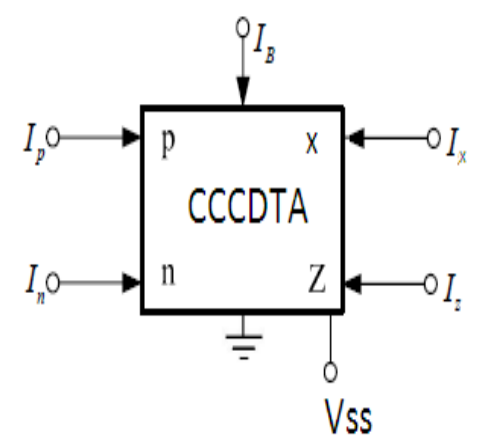

Fig.1 The schematic symbol CCCDTA

Input output relation of CCCDTA in matrix form is shown below.

$$
\left[\begin{array}{c}
V_{p} \\
V_{n} \\
I_{z} \\
\mathrm{I}_{\mathrm{x}}
\end{array}\right]=\left[\begin{array}{cccc}
\mathrm{R}_{\mathrm{p}} & 0 & 0 & 0 \\
0 & \mathrm{R}_{\mathrm{n}} & 0 & 0 \\
1 & -1 & 0 & 0 \\
0 & 0 & \mathrm{~g}_{\mathrm{m}} & 0
\end{array}\right]\left[\begin{array}{c}
\mathrm{I}_{\mathrm{p}} \\
\mathrm{I}_{\mathrm{n}} \\
\mathrm{V}_{\mathrm{z}} \\
\mathrm{V}_{\mathrm{X}}
\end{array}\right]
$$

Its properties are similar to the conventional CDTA, only difference is that input voltages of CCCDTA are not zero and the CCCDTA has finite input resistances $R_{p}$ and $R_{n}$ at the $P$ and $N$ input terminals, respectively. These parasitic resistances are equal and can be controlled by the bias current $I_{b}$ as these are inversely proportional to the biased current. It is shown below in Equation (1).

$$
\mathrm{R}_{\mathrm{p}}=\mathrm{R}_{\mathrm{n}}=\mathrm{A} / \mathrm{I}_{\mathrm{b}}
$$

Here, $\mathrm{A}$ is the proportionality constant.

$\mathrm{I}$ and $\mathrm{V}$ denote current and voltage at terminals, shown at corresponding suffix respectively in matrix. In matrix equation $\mathrm{g}_{\mathrm{m}}$ is the transconductance of the CCCDTA.

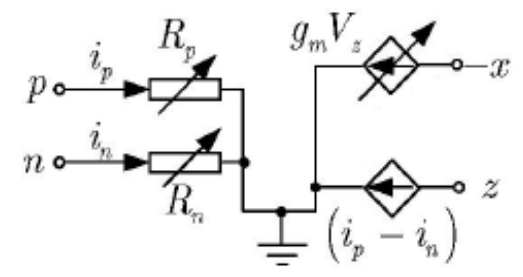

Fig.2 The Equivalent symbol CCCDTA

Another difference is that when bias current $\mathrm{I}_{\mathrm{b}}$ is negative CCCDTA does not conduct any current. This property of CCCDTA is used in the construction of precision rectifier.

Non-Ideal Analysis

For non ideal case, equations in matrix form will be modified as shown in equation (2) and (3).

$$
\begin{aligned}
& \mathrm{I}_{\mathrm{z}}=\alpha_{\mathrm{p}} \mathrm{I}_{\mathrm{p}}-\alpha_{\mathrm{n}} \mathrm{I}_{\mathrm{n}} \\
& \mathrm{I}_{\mathrm{x}}=\beta \mathrm{g}_{\mathrm{m}} \mathrm{V}_{\mathrm{z}}
\end{aligned}
$$




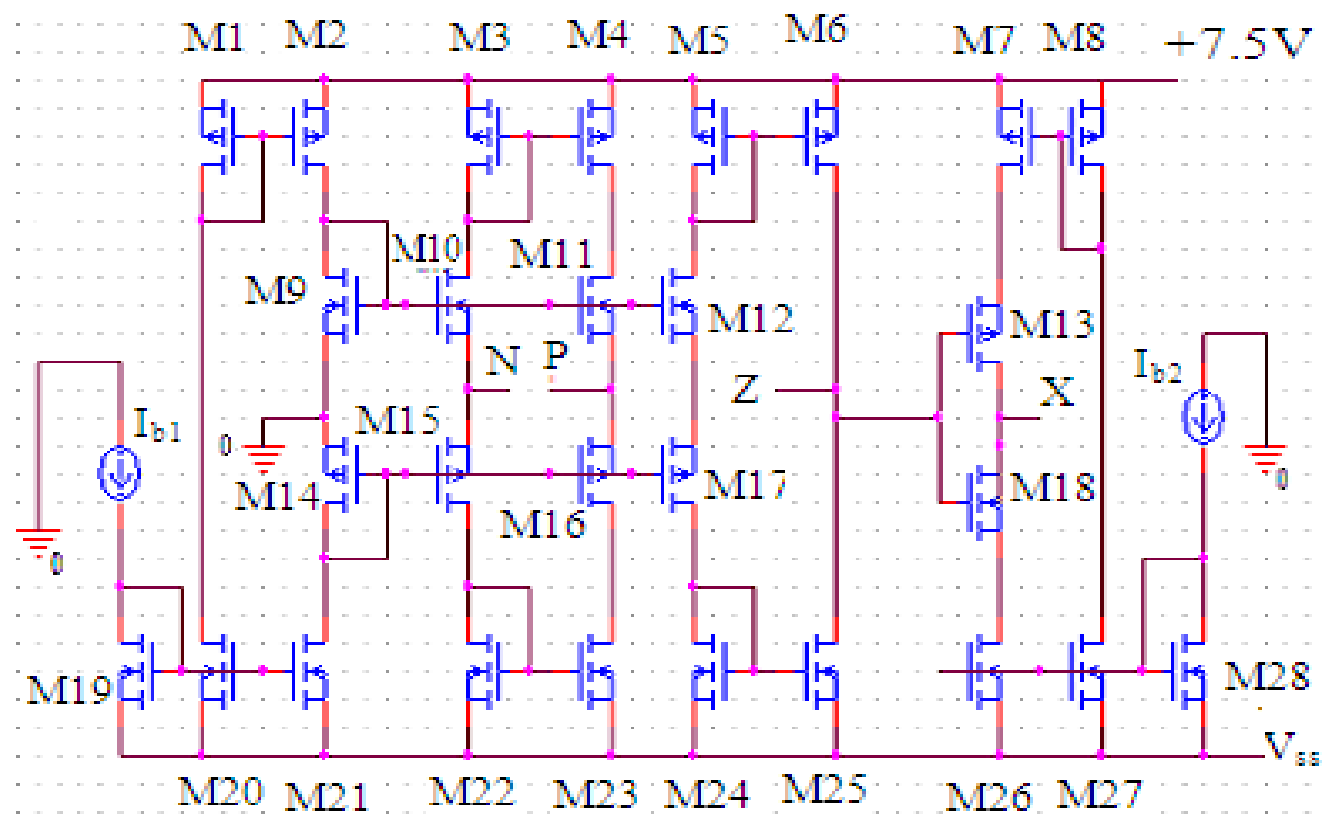

Fig. 3 Proposed CMOS Implementation of CCCDTA

Table: 1 Transistor dimensions of the CCCDTA

\begin{tabular}{|l|l|}
\hline \multicolumn{1}{|c|}{ CMOS Transistors } & $\mathbf{W}(\boldsymbol{\mu m}) / \mathbf{L}(\boldsymbol{\mu m})$ \\
\hline M1 - M4 & $21 / 0.7$ \\
\hline M5 - M6 & $28 / 0.7$ \\
\hline M7, M14-M17, M26, M27 & $56 / 0.7$ \\
\hline M8 & $58.8 / 0.7$ \\
\hline M9-M12, M19-M23, M28 & $7 / 0.7$ \\
\hline M13 & $28.8 / 0.7$ \\
\hline M18 & $16.1 / 0.7$ \\
\hline M24, M25 & $11.2 / 2.1$ \\
\hline
\end{tabular}

III. PROPOSED PRECISION RECTIFIER CIRCUIT

Proposed rectifier is shown in Fig. 4. It consists of two CMOS CCCDTA. Internal circuit design of CCCDTA is given in Fig. 3. In circuit $\mathrm{V}_{\mathrm{b}}$ is the bias voltage for tuning of amplitude and polarity of output signal. $I_{\text {in }}$ is the input current signal and $I_{o}$ is the output current through load $R_{\mathrm{z}} \cdot V_{s s}$ is the terminal for eliminating either positive signal or negative signal. $\mathrm{R}_{\mathrm{x}}$ is resistance connected to the $\mathrm{X}$ terminal.

Same circuit can be used as full wave rectifier and half wave rectifier without any additional circuit. If we want to construct half wave rectifier with positive part of input signal, we have to connect $-1.5 \mathrm{~V}$ to $\mathrm{V}_{\mathrm{ss}}$ terminal of CCCDTA1. Similarly if we want to construct half wave rectifier with negative part of input signal, we connect $-1.5 \mathrm{~V}$ to $\mathrm{V}_{\mathrm{ss}}$ of CCCDTA2.

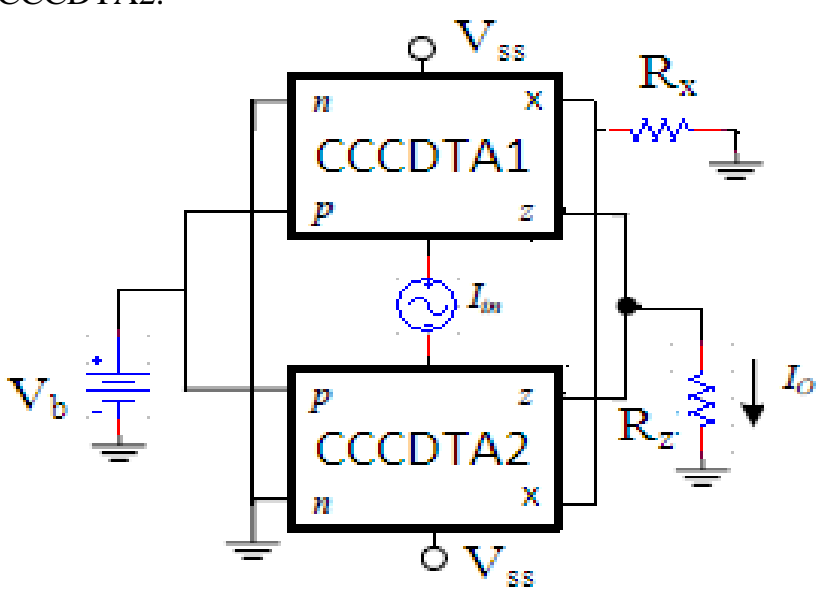

Fig. 4 Proposed Circuit Diagram 


\section{A Full-wave rectifier mode}

Proposed circuit of Fig. 4 works as full wave rectifier when $\mathrm{V}_{\mathrm{ss}}$ terminal of both CCCDTA remains disconnected. It is shown in Fig. 5. For that case,

Hence,

$$
\mathrm{V}_{\mathrm{p} 1}=\mathrm{V}_{\mathrm{p} 2}=\mathrm{V}_{\mathrm{b}}
$$

$$
\mathrm{I}_{\mathrm{p} 1}=\mathrm{I}_{\mathrm{p} 2}=\mathrm{V}_{\mathrm{b}} / \mathrm{R}_{\mathrm{p}}
$$

Substituting, value of $R_{p}$ from equation (1) we get,

$$
\mathrm{I}_{\mathrm{z} 1}=\mathrm{I}_{\mathrm{p} 1}=\left(\mathrm{I}_{\mathrm{b}} \cdot \mathrm{V}_{\mathrm{b}}\right) / \mathrm{A}=\mathrm{C} . \mathrm{I}_{\mathrm{b}}
$$

Where $\mathrm{C}$ is a constant given by $\mathrm{C}=\mathrm{V}_{\mathrm{b}} / \mathrm{A}$.

Similarly,

$$
\mathrm{I}_{\mathrm{z} 2}=\mathrm{I}_{\mathrm{p} 2}=\left(\mathrm{I}_{\mathrm{b}} \cdot \mathrm{V}_{\mathrm{b}}\right) / \mathrm{A}=\mathrm{C} \cdot \mathrm{I}_{\mathrm{b}}
$$

Here we assumed that bias current $\mathrm{I}_{\mathrm{b}}$ is positive only, if we apply sinusoidal current source $\mathrm{I}_{\text {in }}$ in place of bias current $\mathrm{I}_{\mathrm{b}}$, equation (6) and (7) will become as,

$$
\mathrm{I}_{\mathrm{z} 1}= \begin{cases}\mathrm{C} . \mathrm{Iin} & \text { if } \operatorname{Iin}>0 \\ 0 & \text { if } \operatorname{Iin}<0\end{cases}
$$

If $I_{\text {in }}$ is positive for CCCDTA1 then it will be negative for CCCDTA2 and similarly if $I_{\text {in }}$ is negative

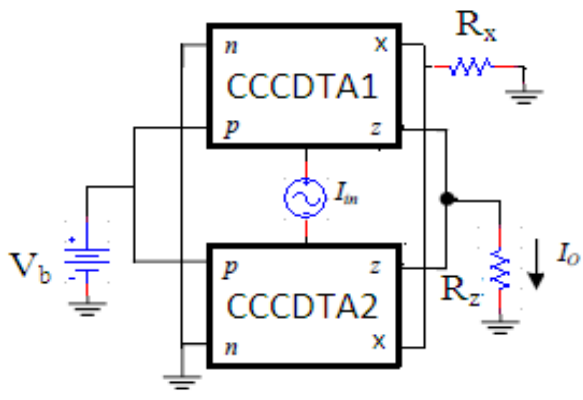

Fig. 5 Proposed Full wave Rectifier

and similarly if $\mathrm{I}_{\mathrm{in}}$ is negative for CCCDTA1 then it will be positive for CCCDTA2. Hence $\mathrm{I}_{\mathrm{z} 2}$ is given by,

$$
\mathrm{I}_{\mathrm{z} 2}= \begin{cases}0 & \text { if } \operatorname{Iin}>0 \\ \mathrm{C} . \mathrm{Iin} & \text { if } \operatorname{Iin}<0\end{cases}
$$

Thus, the output current $I_{o}$ as shown in Fig. 5 is given by equation (10).

$$
\mathrm{I}_{\mathrm{o}}=\mathrm{C} .\left|\mathrm{I}_{\mathrm{in}}\right|
$$

Hence the circuit in Fig. 5 can perform as a precision current-mode full-wave rectifier whose output magnitude and polarity can be controlled by bias voltage $\mathrm{V}_{\mathrm{b}}$. PSPICE simulation for verifying features of full wave rectifier is shown under simulation results.

\section{B Half-wave rectifier mode}

Half wave rectifier with positive input signal only shown in Fig. 6. And half wave rectifier with negative input signal only is shown in Fig. 7. In both circuit $\mathrm{V}_{\mathrm{ss}}$ is connected with $-1.5 \mathrm{~V}$.

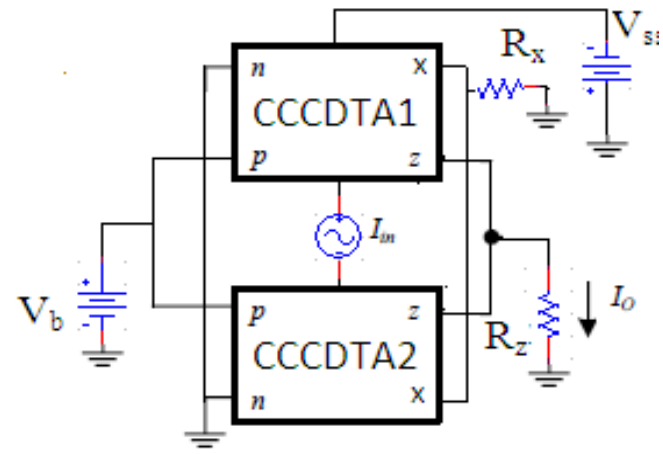

Fig. 6 Proposed Half wave Rectifier with Positive part of Input Signal as Output 


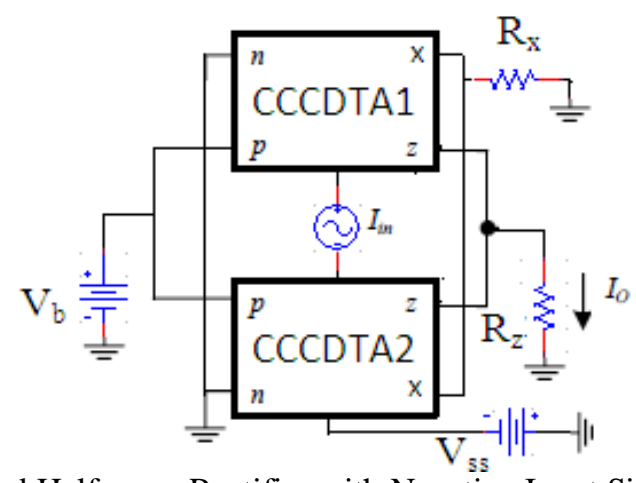

Fig. 7 Proposed Half wave Rectifier with Negative Input Signal as Output

Theory of half wave rectifier is same as full wave rectifier only difference is that $\mathrm{V}_{\mathrm{ss}}$ is in operating mode. Features of half wave rectifier is same as full wave rectifier, hence only 'PSPICE simulation of half wave rectifier action' is presented under simulation results.

\section{Simulation Results}

Performance of the proposed circuit is checked by the Orcad PSPICE simulation program. For proposed rectifier CMOS implementation of CCCDTA is given in Fig. 3 to achieve more precision. The circuit is simulated by using $0.35 \mu \mathrm{m}$ n-well CMOS process provided by TSMC. Aspect ratios of the transistors used are shown in TABLE I. For all simulations $\mathrm{I}_{\mathrm{b} 2}$ of both CCCDTA is connected by a single current source of $25 \mu \mathrm{A}$.

\section{A Simulation Of Full-Wave Rectifier}

For this case $\mathrm{V}_{\mathrm{ss}}$ of both CCCDTA remains disconnected as described previously.

\section{Tuning of amplitude}

Amplitude of output current may be tuned to any value. It is done by changing the magnitude of bias voltage $V_{b}$; it is shown by Fig. 8 to Fig. 12 . For these simulation $I_{i n}$ is of magnitude $25 \mathrm{~mA}$ and frequency 100 $\mathrm{kHz}$ and $\mathrm{R}_{\mathrm{z}}=\mathrm{R}_{\mathrm{x}}=1$.

From these simulations of tuning of amplitude, we can see that by increasing the amplitude of bias voltage $\mathrm{V}_{\mathrm{b}}$ amplitude of output signal increases. At $\mathrm{V}_{\mathrm{b}}=3.5 \mathrm{~V}$ magnitude of output signal is same as input signal.

It may operate with different value of load with variation in magnitude of output signal. On increasing the value of $R_{z}$ of Fig. 5, amplitude of output current $I_{o}$ decreases. It is shown below in Fig. 13 and Fig.14. For these simulations $\mathrm{V}_{\mathrm{b}}$ is set to $3.5 \mathrm{~V}, \mathrm{I}_{\mathrm{in}}$ is having amplitude $25 \mathrm{~mA}$ and frequency $100 \mathrm{kHz}$.

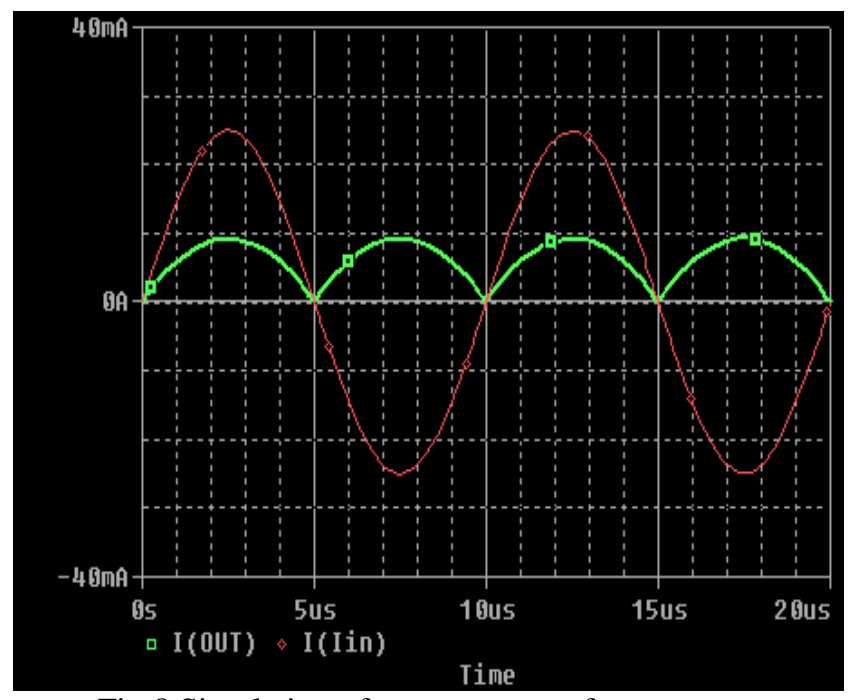

Fig.8 Simulation of output current for $\mathrm{Vb}=0.5 \mathrm{~V}$ 


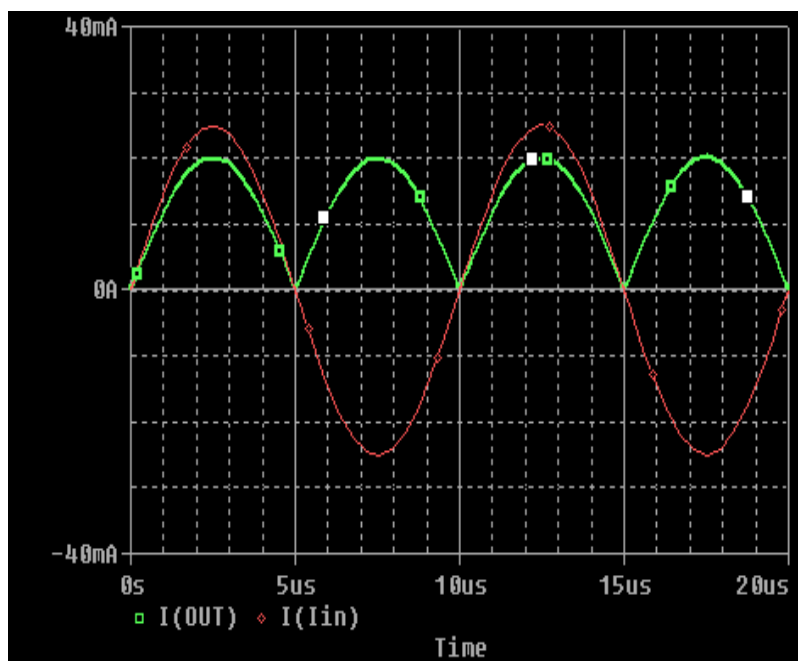

Fig. 9 Simulation of output current for $V b=1.5 \mathrm{~V}$

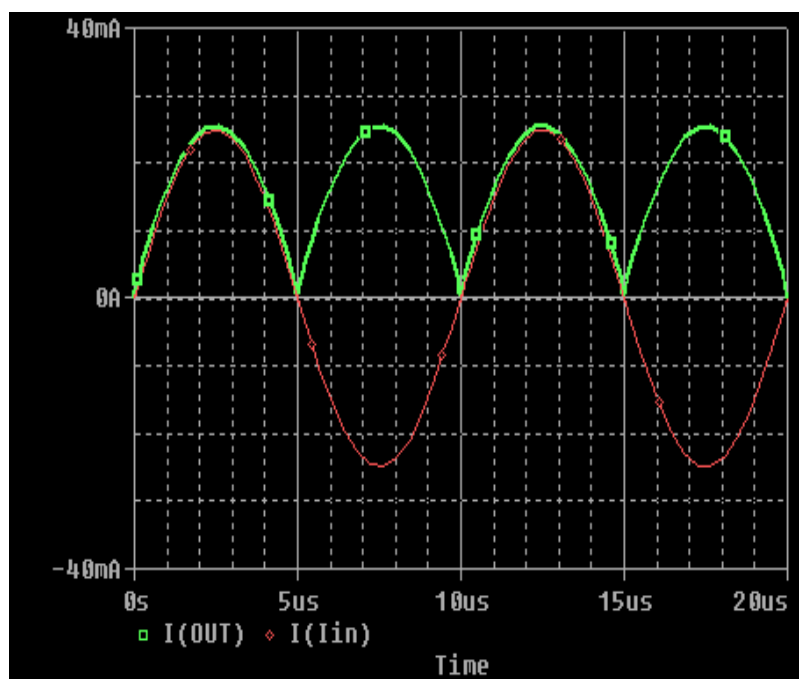

Fig.10 Simulation of output current for $v b=3.5 \mathrm{~V}$

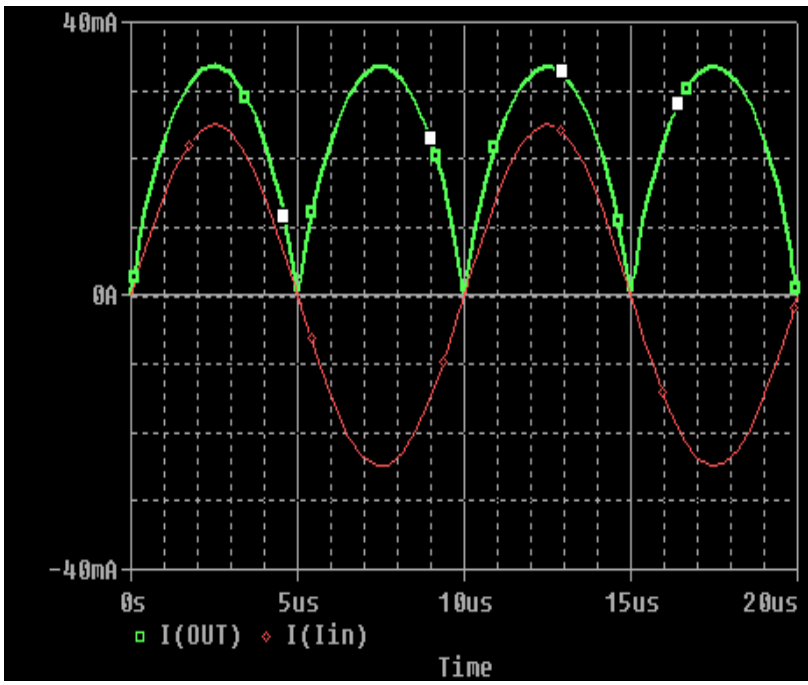

Fig.11 Simulation of output current for $V b=5 \mathrm{~V}$ 


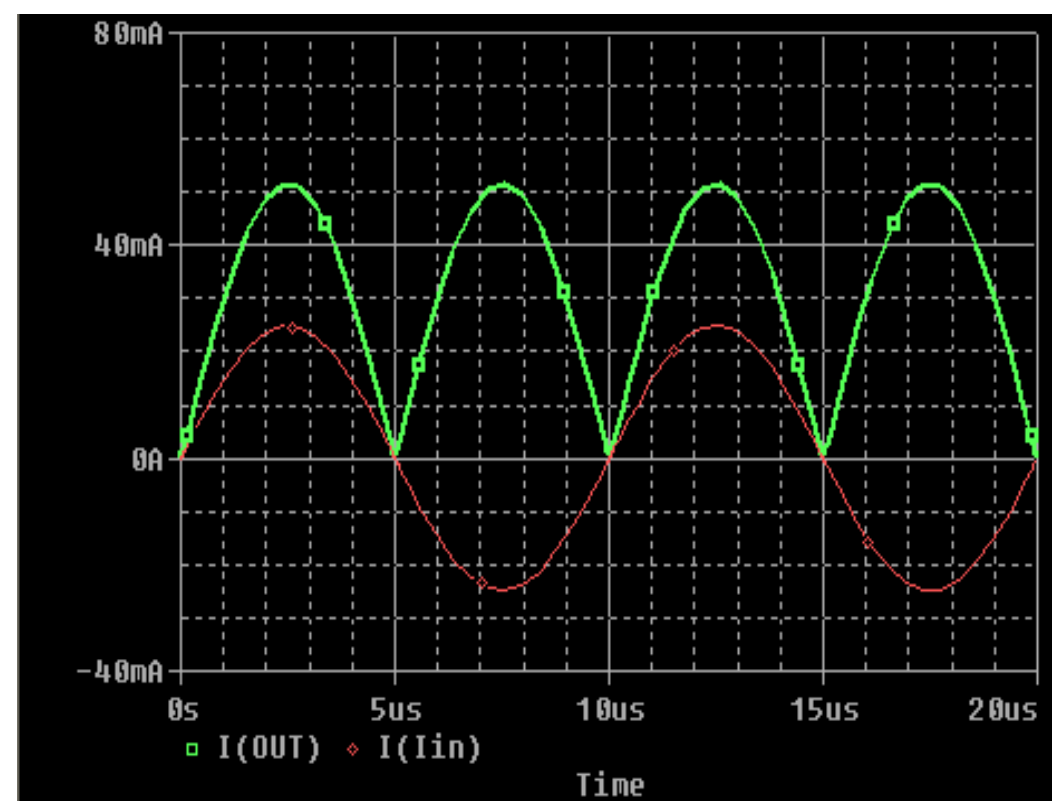

Fig.12 Simulation of output current for $V b=10 \mathrm{~V}$

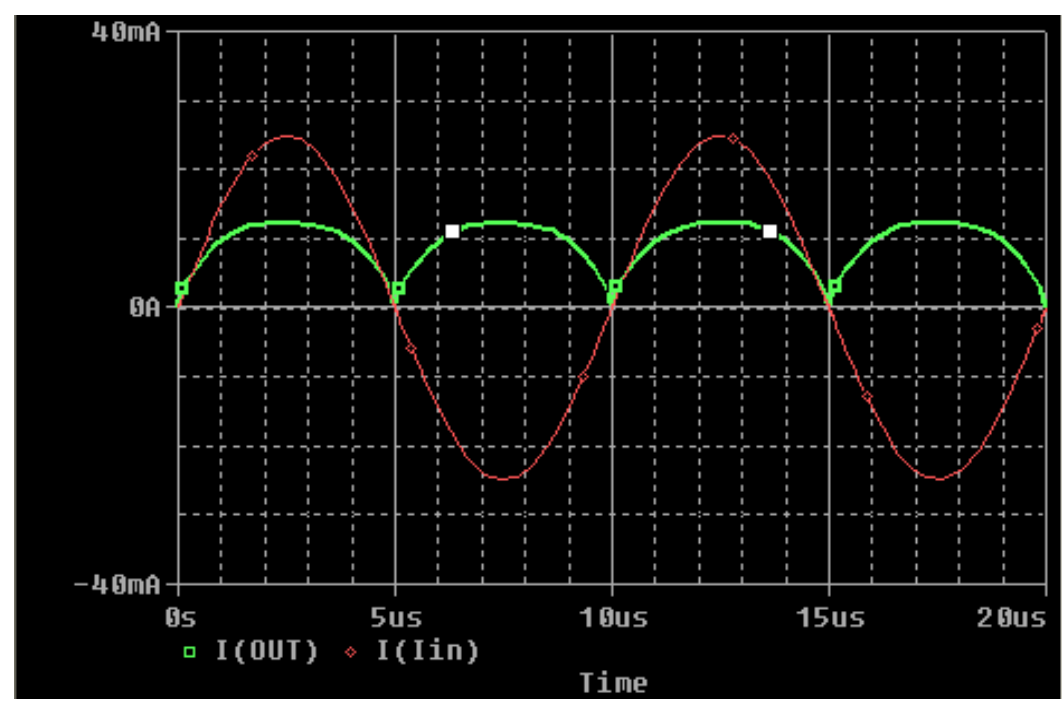

Fig.13 Simulation of output current for $R z=50 \Omega$

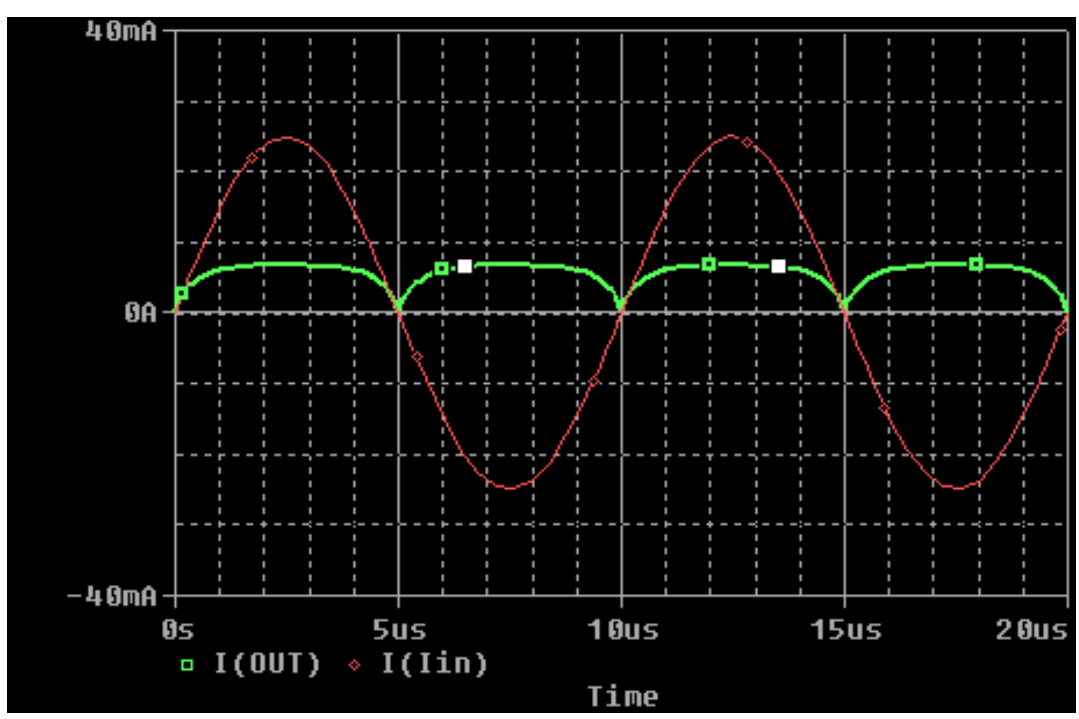

Fig. 14 Simulation of output current for $R z=100 \Omega$ 


\section{Polarity change}

Polarity of output current $I_{o}$ can be changed by changing the polarity of bias voltage $V_{b}$. PSPICE simulation relating these properties is shown in Fig. 15. For this simulation $\mathrm{I}_{\mathrm{in}}$ is of amplitude $25 \mathrm{~mA}$ and of frequency $100 \mathrm{kHz}$ and $\mathrm{R}_{\mathrm{z}}=1$. In Fig. 15 output current $\mathrm{I}_{\text {out }}$ is inverted for the same input current $\mathrm{I}_{\mathrm{in}}$.

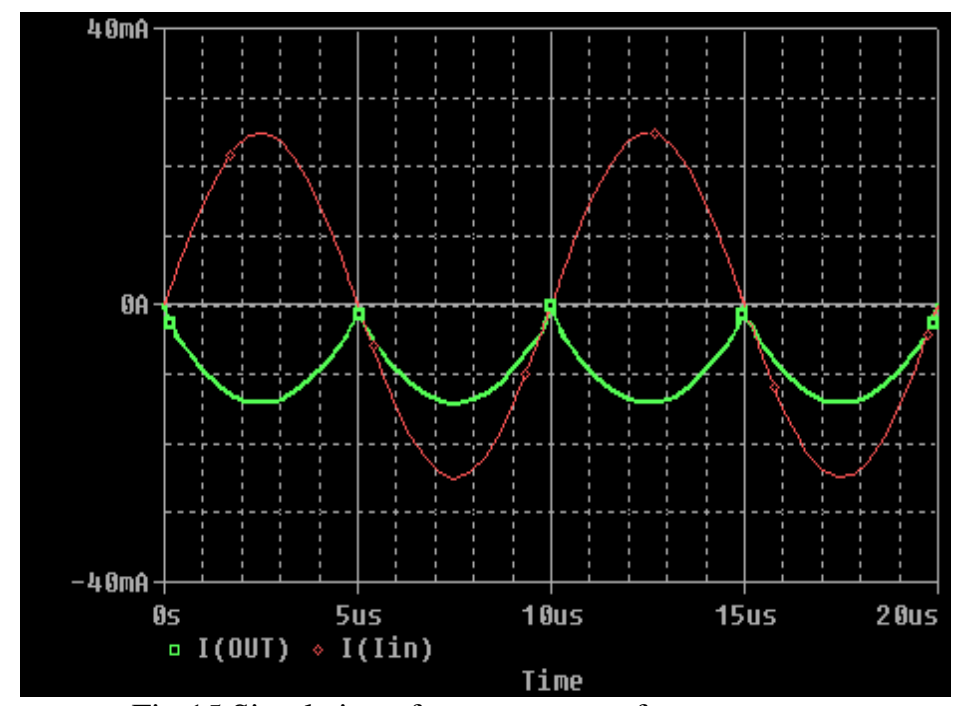

Fig.15 Simulation of output current for $V b=-3.5 \mathrm{~V}$

\section{Input current range}

DC transfer characteristic of the proposed full-wave rectifier at different temperature $\left(25^{\circ} \mathrm{C}, 50^{\circ} \mathrm{C}\right.$ and $\left.75^{\circ} \mathrm{C}\right)$ is shown in Fig. 16 and Fig. 17.

Here ${ }^{\circ}($ Green $),{ }^{\circ}($ Red $)$ and $\nabla$ (Blue) indicate simulation at $25^{\circ} \mathrm{C}, 50^{\circ} \mathrm{C}$ and $75^{\circ} \mathrm{C}$ respectively. For simulation of positive input current source $\mathrm{I}_{\text {in }}$ is varied from -1A to $1 \mathrm{~A}$, it is shown in Fig 16 . From these figure it can be seen that the proposed circuit offers a wide-range of input current to be rectified. In that figure it is linear up to $600 \mathrm{~mA}$, hence it can be used up to this wide range and can rectify without temperature effect.

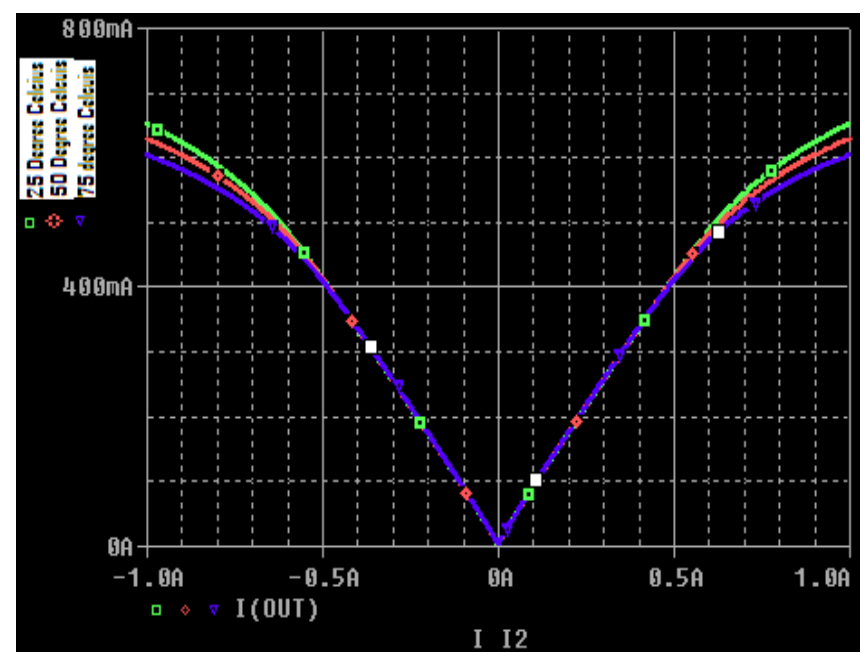

Fig.16 DC transfer characteristics of proposed full wave rectifier for $V b=3.5 \mathrm{~V}$ 


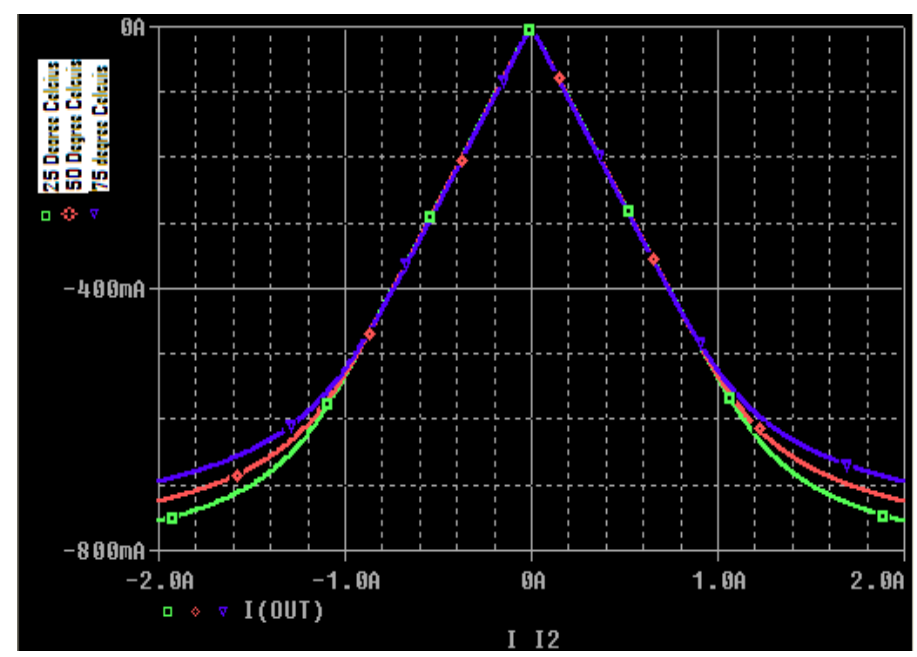

Fig.17 DC transfer characteristics of proposed full wave rectifier for $V b=-3.5 \mathrm{~V}$

For simulation of negative input current source $\mathrm{I}_{\text {in }}$ is varied from -2 A to $2 \mathrm{~A}$, it is shown in Fig. 17. In that figure it is linear up to $1200 \mathrm{~mA}$, hence it can be used up to this wide range and can rectify without temperature effect.

Rectifier circuit works for a wide range of input current. It can also be shown by different input current signal. For different magnitude of input current PSPICE simulation is shown in Fig. 18 to Fig. 22.

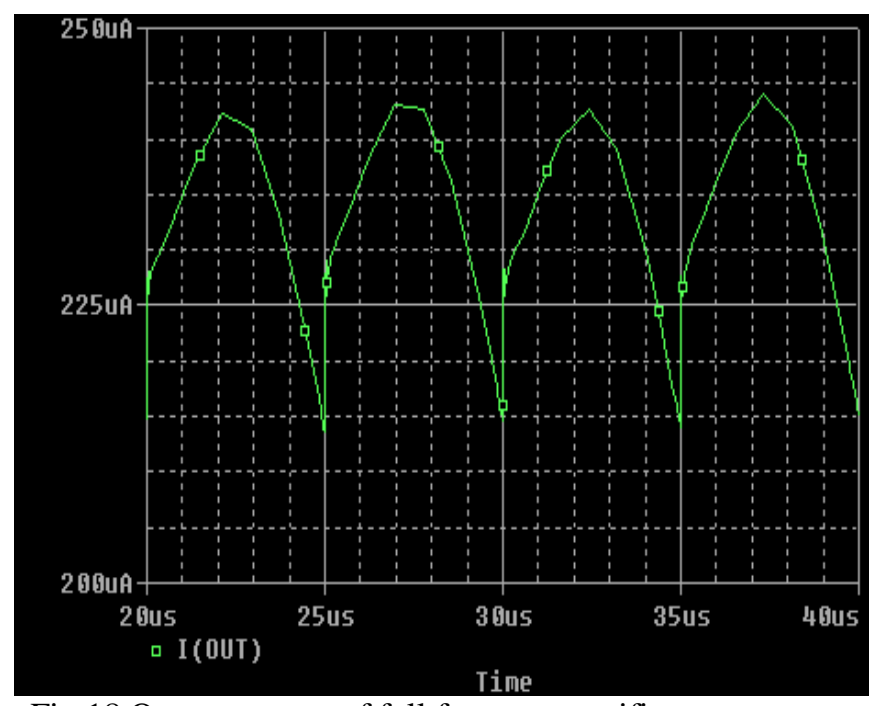

Fig.18 Output current of full for wave rectifier $\operatorname{Iin}=50 \mu \mathrm{A}$

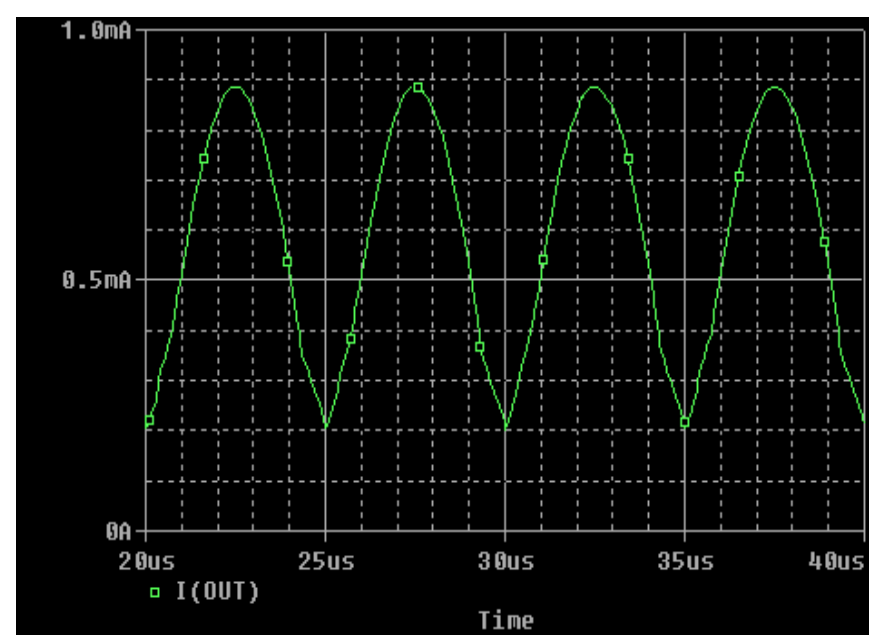

Fig.19 Output current of full wave rectifier for $\operatorname{Iin}=500 \mu \mathrm{A}$ 


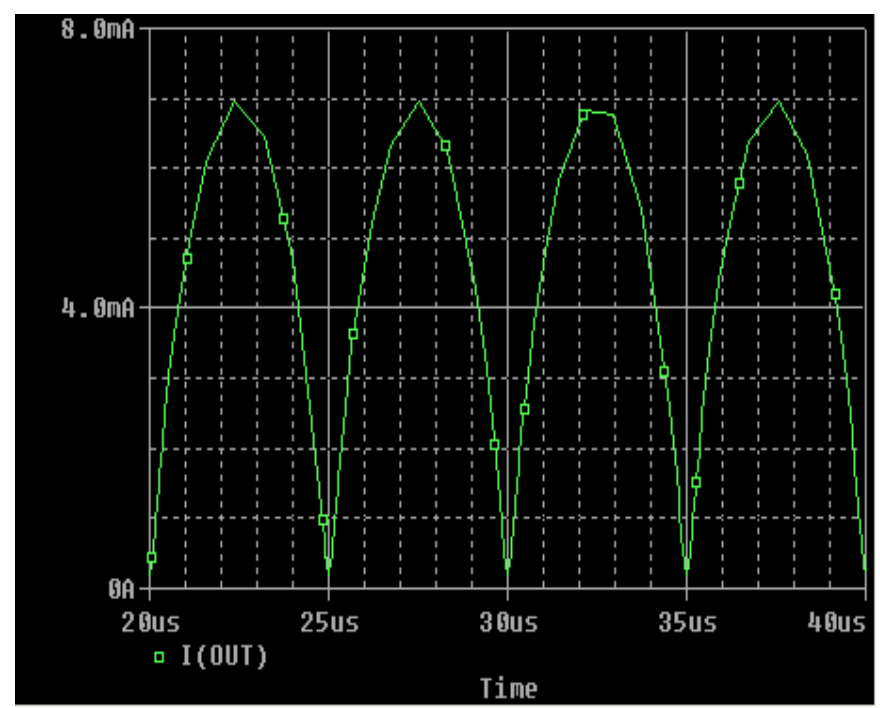

Fig.20 Output current of full wave rectifier for $\operatorname{Iin}=5 \mathrm{~mA}$

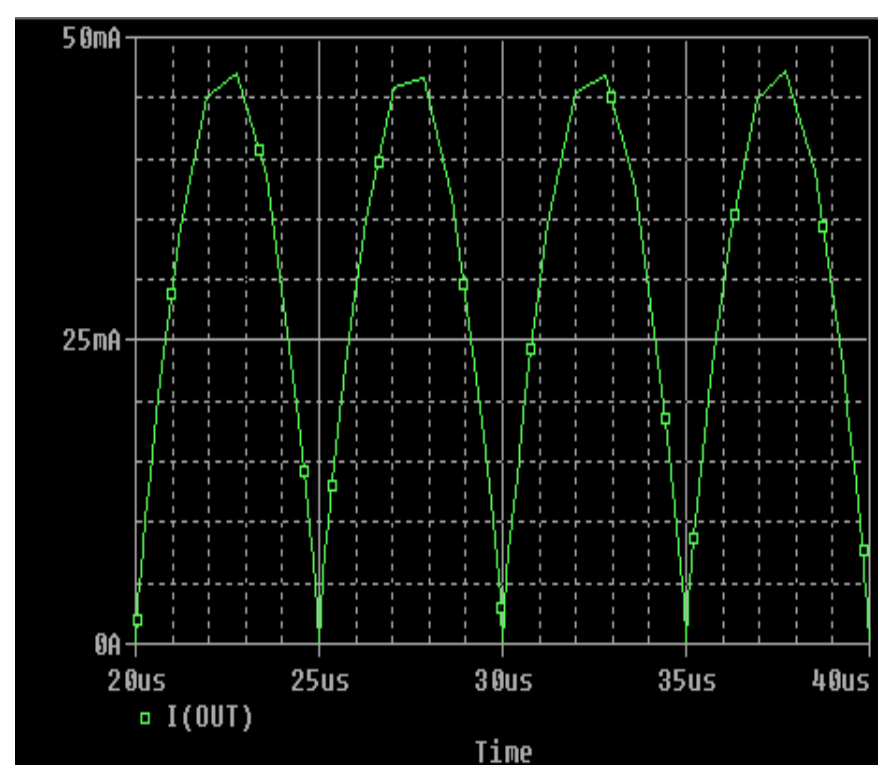

Fig.21 Output current of full wave rectifier for $\operatorname{Iin}=50 \mathrm{~mA}$

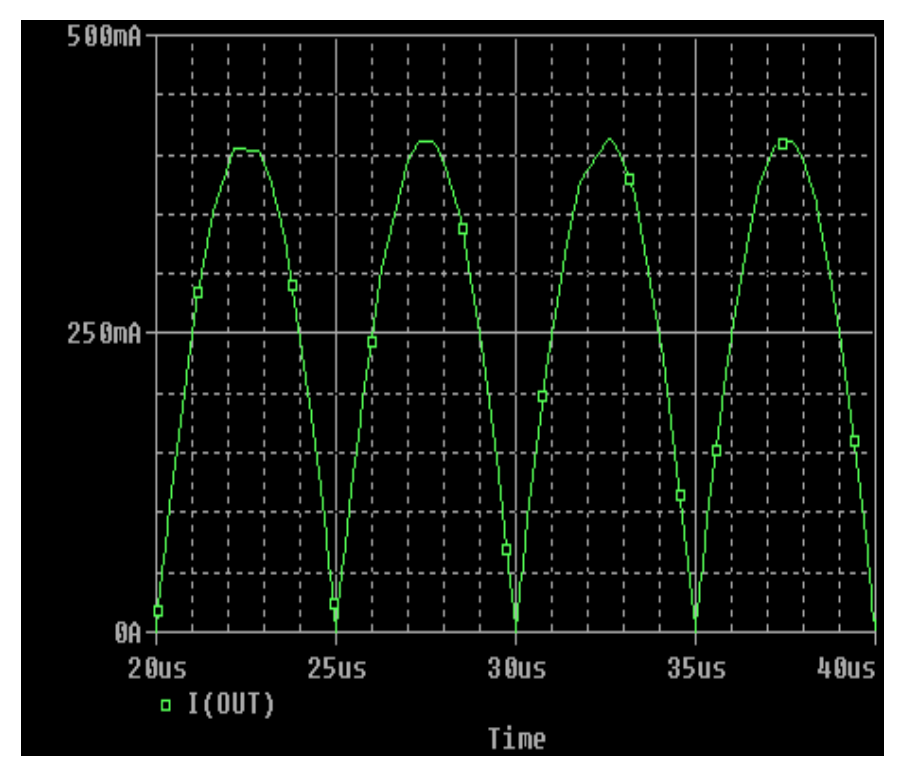

Fig.22 Output current of full wave rectifier for $\operatorname{Iin}=500 \mathrm{~mA}$ 


\section{Frequency range}

It performs well over wide range of frequency. It is shown in the Fig. 23 to Fig. 28 below for different temperature $\left(25^{\circ} \mathrm{C}, 50^{\circ} \mathrm{C}\right.$ and $\left.75^{\circ} \mathrm{C}\right)$. For all these simulation $\mathrm{I}_{\mathrm{in}}$ is of magnitude $25 \mathrm{~mA}$. Bias voltage $\mathrm{V}_{\mathrm{b}}$ is set to $1.5 \mathrm{~V}$ so that amplitude of input and output current may be seen differently. Here, $\square$ and $\Delta$ indicates simulation at $25^{\circ} \mathrm{C}$ for $\mathrm{I}_{\text {out }}$ and $\mathrm{I}_{\text {in }}$ respectively. ${ }^{\circ}$ and $\square$ indicates simulation at $50^{\circ} \mathrm{C}$ for $\mathrm{I}_{\text {out }}$ and $\mathrm{I}_{\text {in }}$ respectively. $\nabla$ and + indicates simulation at $75^{\circ} \mathrm{C}$ for $\mathrm{I}_{\text {out }}$ and $\mathrm{I}_{\text {in }}$ respectively.

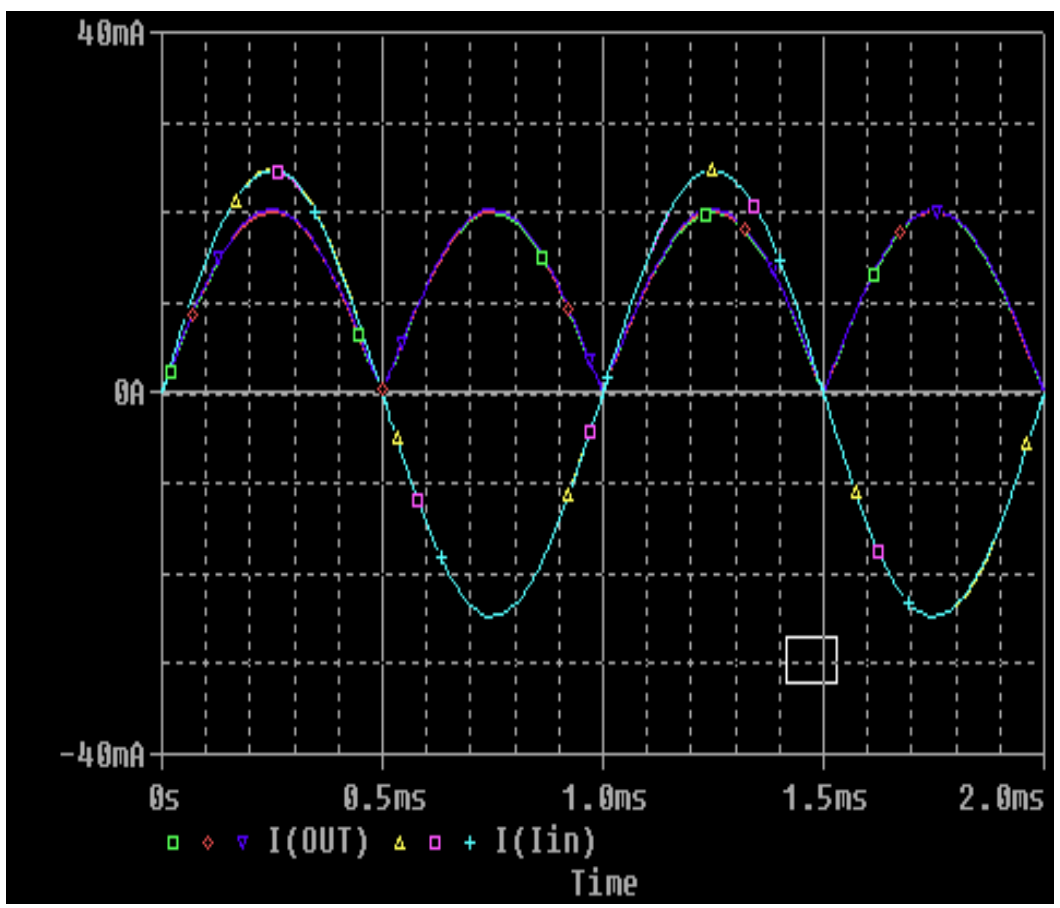

Fig.23 Output Current for Frequency $1 \mathrm{kHz}$

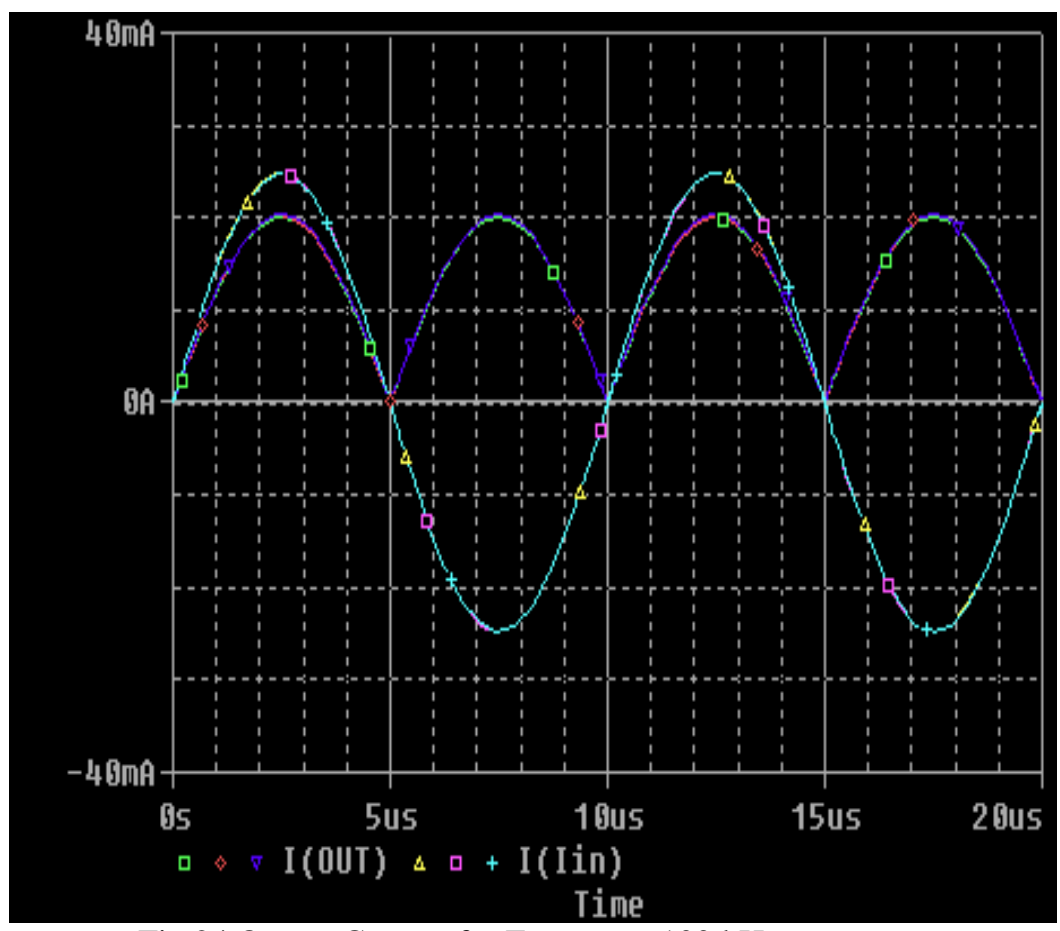

Fig.24 Output Current for Frequency 100 kHz 


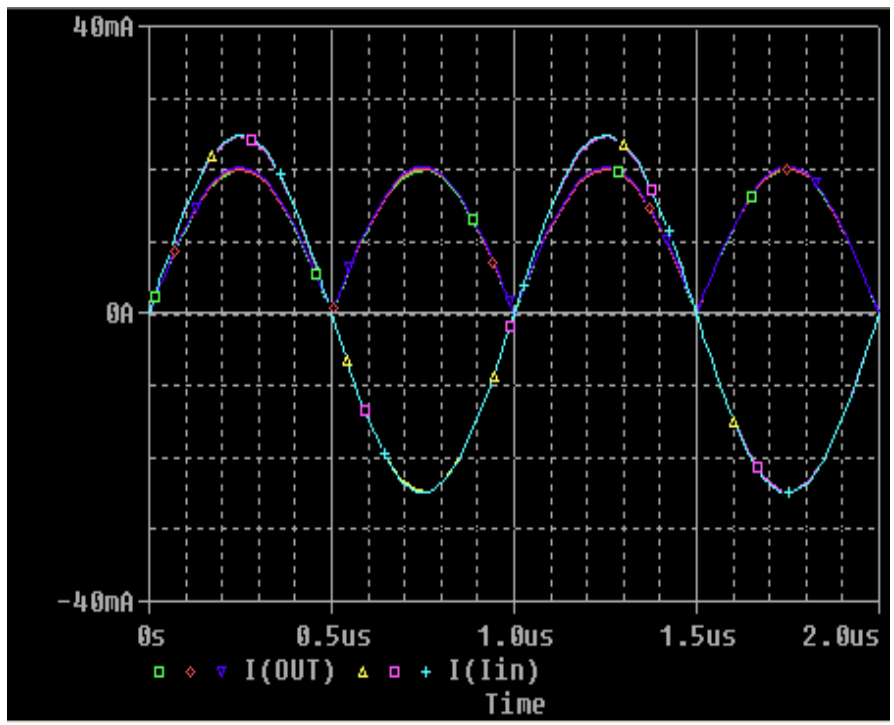

Fig. 26 Output Current for Frequency 1MHz

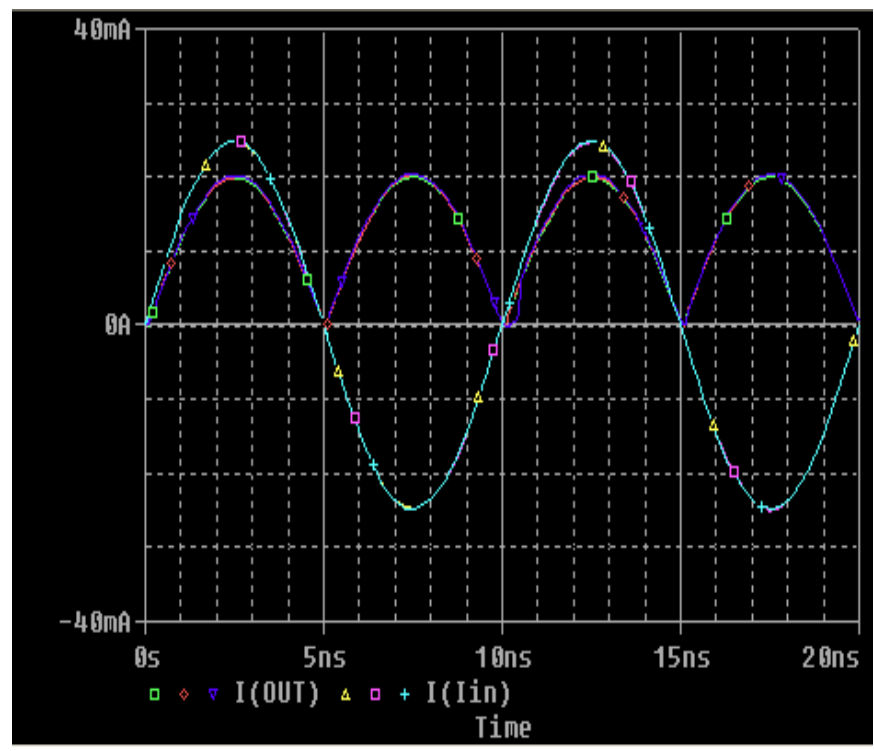

Fig. 27 Output Current for Frequency 100MHz

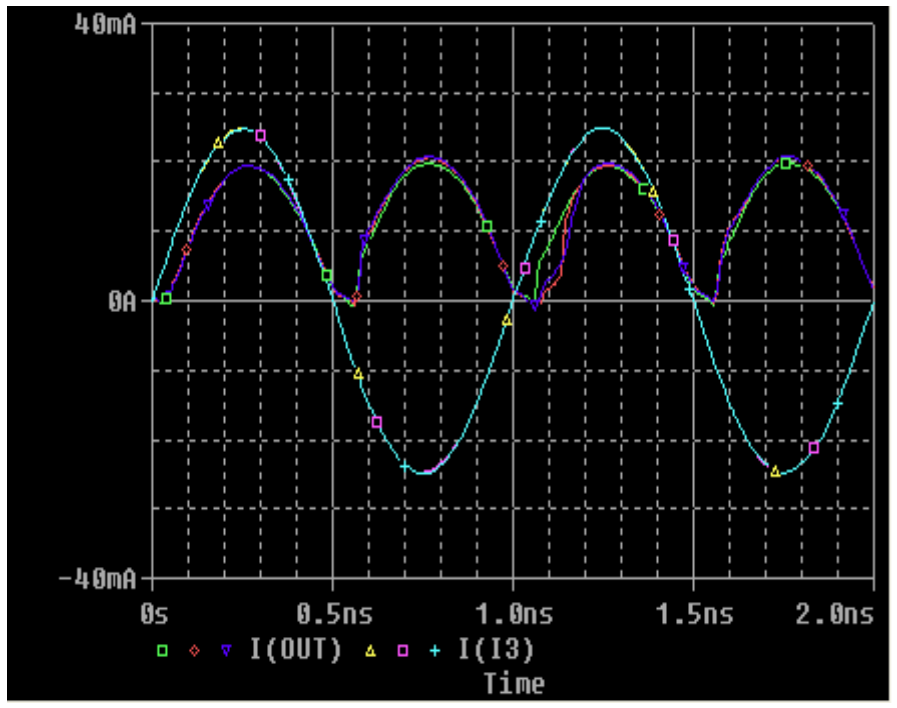

Fig.28 Output Current for Frequency $1 \mathrm{GHz}$ 


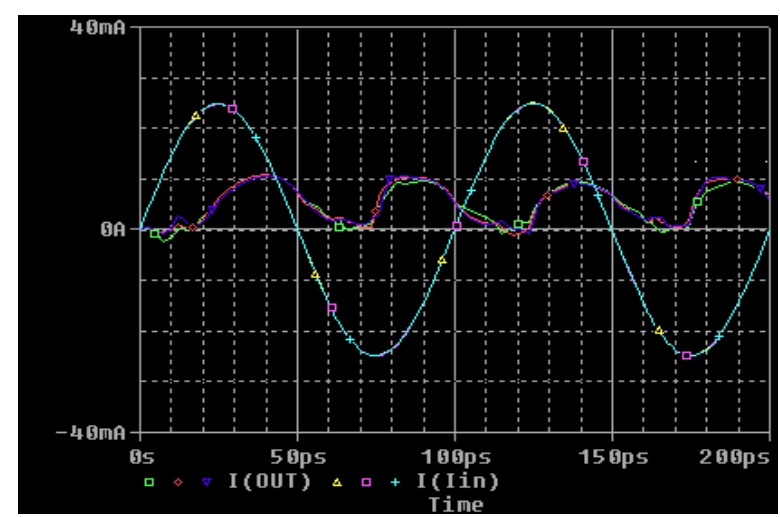

Fig.28 Output Current for Frequency $10 \mathrm{GHz}$

These simulations show that rectifier circuit work for frequency up to tens of Giga Hertz with low temperature sensitivity.

\section{B Simulation of half-wave rectifier}

By connecting $\mathrm{V}_{\mathrm{ss}}$ of any one CCCDTA to $-1.5 \mathrm{~V}$ we will get half wave rectified output. Simulation of this circuit is shown in Fig. 29 and Fig.30 to show the half wave rectifier action only. Other features are not shown as they are similar to full wave rectifier. For simulation $\mathrm{V}_{\mathrm{b}}$ is set to $3.5 \mathrm{~V}$ and $\mathrm{I}_{\mathrm{in}}$ is having magnitude $25 \mathrm{~mA}$ and frequency $100 \mathrm{kHz}$.

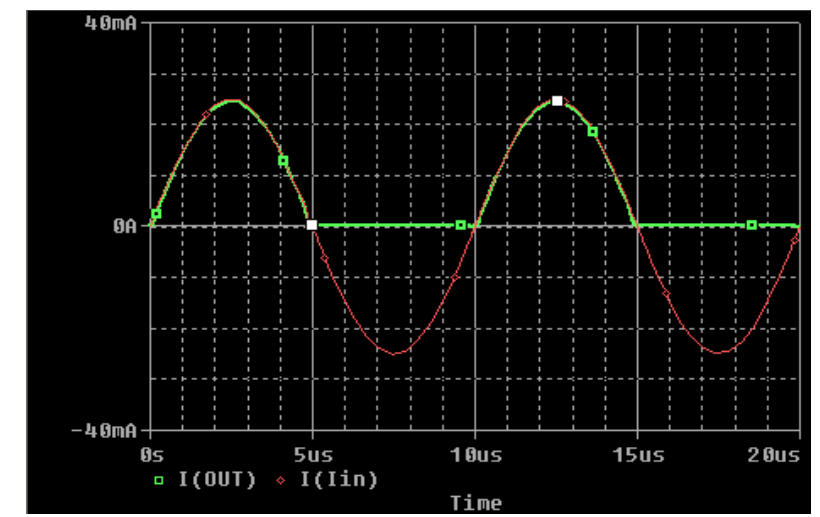

Fig.29 Output Current with $\mathrm{V}_{\mathrm{ss}}$ of CCCDTA1 connected to -1.5V

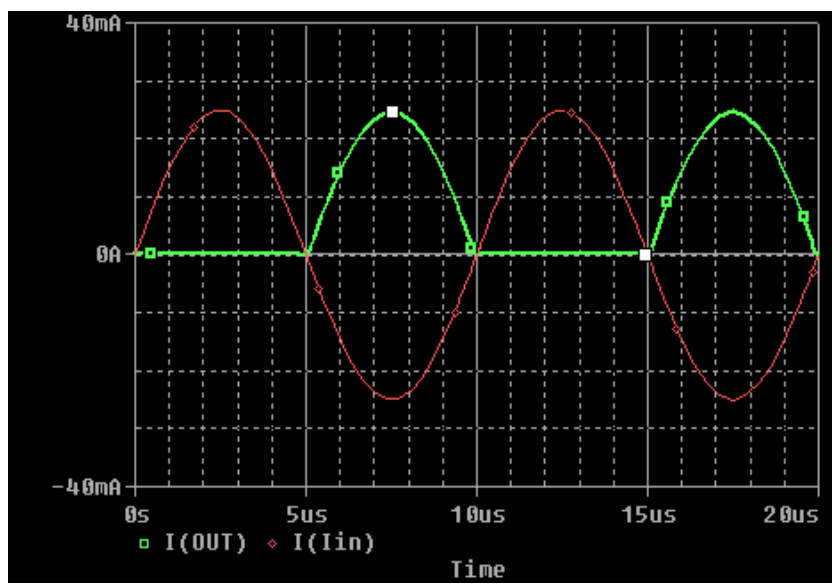

Fig.30 Output Current with $\mathrm{V}_{\mathrm{ss}}$ of CCCDTA2 connected to $-1.5 \mathrm{~V}$

This shows that in case of half wave rectifier we may either produce positive signal or negative signal. It has also features of tuning of amplitude, polarity change of output current, wide operating current amplitude (shown by DC characteristics of full wave rectifier) and frequency range similar to full wave rectifier as there is no change in the circuitry. 


\section{Conclusion}

The precision current mode rectifier, based on CCCDTA, that can rectify an input current with electronic controllability of output current's magnitude and polarity by tuning the magnitude and polarity of the bias voltage has been reported in this paper. PSPICE simulation results confirm that the proposed circuit provides a wide range of frequency operation with very low temperature sensitivity, controllability of the magnitude of output current and polarity by an input bias voltage.

PSPICE simulations confirm tuning ability and polarity action of output current. It is also clear that the proposed rectifier is temperature insensitive.

It also shows that the same circuit can work as full wave rectifier mode and half wave rectifier mode. In case of half wave rectifier, there is the control on the rectification part of the input signal; it means we can rectify either positive input signal or negative input signal by applying $\mathrm{V}_{\mathrm{ss}}$ voltage on either $1^{\text {st }}$ CCCDTA or $2^{\text {nd }}$ CCCDTA.

It performs well over wide range of input current magnitude that is shown in the DC characteristic by wide range of linear portion. They show that the proposed circuit can function as a current-mode precision fullwave rectifier, where input current range of $-600 \mathrm{~m}$ A to $600 \mathrm{~m} \mathrm{~A}$ in positive rectification mode and $-1000 \mathrm{~mA}$ to $1000 \mathrm{~mA}$ in negative mode.

PSPICE simulations also show, It has operating frequency range is from $1 \mathrm{kHz}$ to tens of Giga Hertz. The total power consumption is $601.05 \mu \mathrm{W}$. With the claimed outstanding features, it is very appropriate to develop the proposed circuit to be a part of a monolithic chip for working in a current-mode signal processing circuit/system. Thus it can be applied in an automatic control by a microprocessor

\section{REFERENCES}

[1] R. F. Coughlin and F. Drisol, Operational Amplifier and Linear Integrated Circuit, $1^{\text {st }}$ ed. New Delhi, India.

[2] CICEKOGLU, M. O., KUNTMAN H. "On the design of CCII+ based relaxation oscillator employing single grounded passive element for linear period control, "Microelectronics Journal , vol. 29, 1999, pp. 993-999.

[3] DI CATAlDO, G. PALUMBO, G. PENISSI, S. "A Schmitt trigger by means of CCII+, "Int. Journal of Circuit Theory and Applications, vol. 23,1995, pp. 161-165.

[4] CAM, U.TOKER, A. CICEKOGLU, O. KUNTMAN H., "Current-mode high output impedance sinusoidal oscillator configuration employing single FTFN,” Anal. Integr. Circuits Signal Process, vol. 24,2000, pp. 231-238.

[5] CHANG, C. M., AL-HASHIMI, B. M., CHEN, H. P., TU, S. H., WAN, J. A. "Current mode single resistance controlled oscillators using only grounded passive components," Electron. Lett., 2002.

[6] SENANI, R., SINGH, V. K., SINGH, A. K., BHASKAR, D. R. "Novel electronically controllable current-mode universal biquad filter," IEICE Electronics Express, vol. 1, no. 14,2004, pp. 410-415.

[7] TOUMAZOU, C., LIDGEY, F. J., HAIGH, D. G. “Analogue IC Design: The current mode approach,” IEE Circuits and Systems Series 2. Peter Peregrinus Ltd., 1990.

[8] CCII01 current conveyor amplifier. Data sheet, LTP Electronics Ltd., Oxford, UK, 1993.

[9] Jaroslav Koton, Norbert Herencsar, KamilVrba, "Current-Mode Precision Full-Wave Rectifier Using Single DXCCII and Two Diodes", IEEE, 2011

[10] TOUMAZOU, C., LIDGEY, F. J., CHATTONG, S. "High frequency current conveyor precision full-wave rectifier,"Electron. Lett., vol. 30, no.10,1994, pp. 745-746.

[11] MANNAMA, V., WILSON, B. “Improved biasing error in currentmode absolute value circuits,"Proc. of the ECCTD'99. Stresa), Sept 1999, pp. 655-658.

[12] STIURCA, D. "Truly temperature independent current conveyor precision rectifier". Electron. Lett., vol. 31, no. 16,1995, pp. 13021303.

[13] BIOLEK, D., HANCIOGLU, E., KESKIN, A.Ü. "High-performance current differencing transconductance amplifier and its application in precision current-mode rectification," Int. J. Electron. Commun.(AË̈), vol. 62, no. 2, 2008 , pp. 92-96.

[14] A. Monpapasorn, K. Dejhan and F. Cheevasuvit, "A full-wave rectifier using a current conveyor and current mirror," Inter. J. Electron., vol. 88, 2001, pp. 751-758.

[15] G. Gift Stephan, "New precision rectifier with high accuracy and wide bandwidth,” Inter. J. Electron., vol. 92, 2006 , pp. 601-617.

[16] S. Khucharoensin and V. Kasemsuwan, "High performance CMOS current-mode precision full-wave rectifier (PFWR)," IEEE Transactions on Circuits and Systems I, vol. 1, 2003, pp. 41-44.

[17] K. Anuntahirunrat, W. Tangsrirat, V. Riewruja and V. Surakampontorn, "Sinusoidal frequency doubler and full-wave rectifier based on translinear current-controlled current conveyors," Inter. J. Electron., vol. 91, 2004, pp. 227-239.

[18] V. Riewruja and R. Guntapong, “A low-voltage wide-band CMOS precision full-wave rectifier,” Inter. J. Electron., vol. 89, 2002, pp. $467-476$

[19] A. Anwar, M. Khan, Abou el-ela and M.A. AL-turaigi, “Current-mode precision rectifier,” Inter. J. Electron., vol. 79, 1995, pp. 853-859.

[20] LIDGEY, F. J., HAYATLEH, K., TOUMAZOU, C. "New current- mode precision rectifiers," In Proc IEEE Int. Symp. Circuits and Systems. Chicago, 1993 pp. 1322-1325.

[21] TILIUTE, D. E. "Full-wave current-mode precision rectifiers using unity-gain cells,"ElektronikaiElektrotechnika, vol. 49, no. 7, 2003, pp. 26-29.

[22] DUKIČ, S. "The analysis of full-wave wide-band precision rectifier with modified second type current conveyor". Facta Universitatis (NIŠ), Ser.: Elec. Energ., vol. 20, no. 2, 2002, pp. 215-221.

[23] TILIUTE, D. E. "On the current-mode rectification. Annals of the "Stefan cel Mare”, University of Suceava, Romania, Electrical Section, no. 11,1999, pp. 61-65.

[24] J. G. Gift Stephan, "Novel precision full-wave rectifier," Proc. of $7^{\text {th }}$ IEEE Inter. Con. on circuit and system, vol. 1, 2000, pp. 206209 